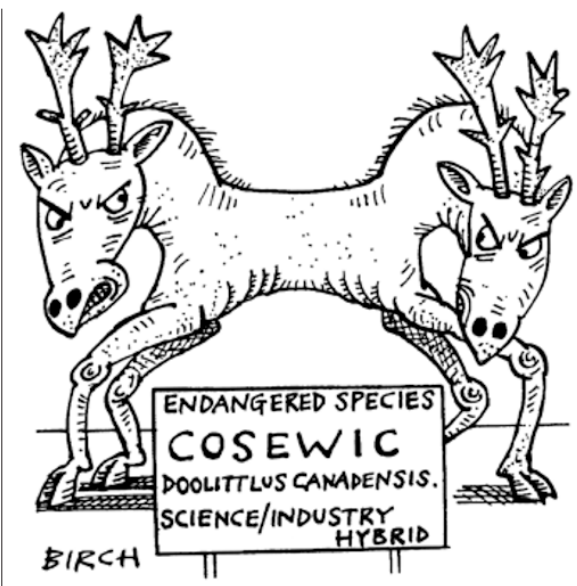

would no longer be able to release its endangered species list independently, but could only do so jointly with federal and provincial wildlife ministers, and the new Canadian Endangered Species Conservation Council.

Sarah Dover, director of the Canadian Endangered Species Campaign for the Canadian Nature Federation, says that, because the council is a political body, "there could be political interference".

But David Brackett, director-general of the federal Canadian Wildlife Service, maintains that adding corporate representatives would not interfere with the committee's independence.

David Spurgeon

\title{
Spanish university chiefs blast recruitment system
}

\section{Barcelona}

A survey by Spain's Council of Universities has revealed widespread dissatisfaction among university heads with the procedures for faculty appointments (see Nature 396, 709 \& 712; 1998).

The results of the survey were revealed by Jorge Fernández-Díaz, state secretary of education and universities, during a meeting in Santander this month on the future of university government.

The survey polled the Council of Universities, whose members include university vice-chancellors, heads of regional education departments, and 15 other members and presidents of the Social Councils - bodies that supervise university departments about recruitment, funding and the performance of university governing bodies.

University appointment boards have five members, two of whom belong to the recruiting university. Three votes are needed to approve an appointment, and most observers — including government and university officials - agree that it is usually easy to secure the third vote for a favoured local candidate.

Of those surveyed, 84 per cent disagreed that "the system of access to professorial posts is appropriate for an effective selection of research and teaching personnel". Asked about the composition of the evaluation panels, most said that the number of members chosen by lot should be increased.

Fifty-eight per cent said that at least four members should be chosen this way, and seven per cent said all five members should be chosen by lot. Only eight per cent thought the current system should be maintained.

One in five said that there should be an increase in the number of members designated by the university at which the appointment is being made, and 15 per cent said that all members should be designated by the university.

Leonardo Sánchez-Ferrer of the Universidad Complutense de Madrid, who carried out the survey, says that demands for greater autonomy in universities are traditionally louder in nationalistic regions such as Catalonia, which could lead to resistance to change.

Mariano Rajoy, minister of education and culture, told the Santander meeting that "a profound and integral change" is needed in the university reform law. Xavier Bosch

\section{Geographer sues critics of his rock-dating methods}

\section{San Diego}

An Arizona State University (ASU)

geographer under federal investigation for possible scientific misconduct is suing the authors of an article in Science that claimed that the geographer's rock-dating methods were fundamentally flawed.

According to court records, Ronald Dorn contends that the authors "intentionally manipulated, omitted and misrepresented data for the purpose of making it appear [Dorn] engaged in professional misconduct and impropriety". The authors include leading Earth scientists from the University of Arizona and Columbia University.

The article reported that 80 of Dorn's samples of rock varnish contained what appeared to be pieces of coal and charcoallike material (see Science 280, 2132-2135; 1998). Mixing these substances — which have widely differing radiocarbon dates can produce any desired date for a sample.

Dorn's dating method involves scraping varnish off rocks and employing radiocarbon labs to date samples from geological formations and rock art sites.

Some authors of the Science article first reported suspicions about Dorn in 1996 to the Office of the Inspector General of the National Science Foundation (NSF), which funded much of Dorn's research on the questioned samples of rock varnish (see Nature 392, 218-219; 1998).

ASU has completed its investigation of Dorn, according to a university official, and sent its findings to the NSF's inspectors, who will determine whether any misconduct occurred. Neither ASU nor NSF officials would disclose the university's conclusions, nor comment on the probe.

Dorn filed his lawsuit on 25 June, a day before the statute of limitations would have expired for filing a complaint about the Science article. Dorn's attorney, Terry Hall, did not respond to interview requests.

Dorn's lawsuit was filed against Warren Beck, Douglas J. Donahue, A. J. T. Jull and George Burr, of the University of Arizona's NSF-funded Accelerator Mass Spectrometer Laboratory; Wallace S. Broecker of the Lamont Doherty Earth Observatory at Columbia University, which is also a named defendant; and Ekkehart Malotki of Northern Arizona University.

Dorn also sued the wives of the scientists, in an apparent attempt to maximize potential economic recovery and pressure. But the lawsuit does not name Eidgenössische Technische Hochschule, the Swiss institution whose staff contributed to the Science article.

Tommy Thompson, the University of Arizona's attorney for that campus's authors, declined to comment, as did those of the authors contacted by Nature. The authors have denied previous contentions by Dorn that they manipulated results to impugn him. Court records show that Dorn's attorney has not served the authors with the lawsuit, which officially starts the court process before a judge. The attorney must serve the defendants within 120 days from 25 June or risk dismissal of the case.

Dorn is suing for defamation, intentional infliction of emotional distress and interference with prospective economic advantage. In the latest twist in the case, on 21 September Dorn's attorney filed a claim - a prelude to a lawsuit - against the University of Arizona and its authors, alleging that they mislabelled, confused or contaminated 96 rock samples submitted for radiocarbon dating. Dorn is seeking $\$ 482,542$ in damages.
Rex Dalton 